\title{
Systemic Model of Implementation of the Blended Learning Modality in the Social Sciences and Education Careers at the Ecuadorian University
}

\author{
JUAN CARLOS CHANCUSIG CHISAG ${ }^{1,}$ \\ Facultad de Ciencias Humanas y Educación \\ Universidad Técnica de Cotopaxi \\ Latacunga, Ecuador \\ MELQUIADES MENDOZA PEREZ ${ }^{2}$, \\ Facultad de Ciencias Humanas y Educación \\ Universidad Técnica de Cotopaxi \\ Latacunga, Ecuador \\ OLGA LORENA GONZALEZ ORTIZ ${ }^{3}$, \\ Facultad de Ciencias Humanas y Educación \\ Universidad Técnica de Cotopaxi \\ Latacunga, Ecuador \\ OSCAR ALEJANDRO GUAYPATIN PICO ${ }^{4}$ \\ Facultad de Ciencias de la Ingeniería y Aplicadas \\ Universidad Técnica de Cotopaxi \\ Latacunga, Ecuador
ROBERTO CARLOS ARIAS FIGUEROA ${ }^{5}$,
Facultad de Ciencias Administrativas
Universidad Técnica de Cotopaxi \\ Latacunga, Ecuador \\ MANUEL WILLIAM VILLA QUISHPE ${ }^{6,}$ \\ Facultad de Ciencias de la Ingeniería y Aplicadas \\ Universidad Técnica de Cotopaxi \\ Latacunga, Ecuador
}

\begin{abstract}
Systemic model of implementation of the blended learning modality in the Social Sciences and Education careers of the Ecuadorian university, which is argued and constructed from the epistemic references of the systemic approach, has the purpose of revealing and socializing the systemic dynamics of the process of implementation of the blended learning modality in the Ecuadorian university and its formative logic, conditioned by the essential relationships that occur between the subsystems that comprise it. The methodology used for the construction of the model is based on the systemic method and for the analysis of feasibility on the criterion of users, who contribute evaluative criteria with scores between good and excellent, which allows to sustain that the proposed model presents a suitable argumentation, a correct structuring, internal logic of cardinal importance that satisfies the demands of its implementation in the management of the process of professional formation in the semipresential modality, guaranteed by an integral fashion of 4 equivalent to good and an integral average of 4 . 46 equivalent to very good, with a tendency to excellence
\end{abstract}

Key Words: systemic model, blended, training, professional.

Received: May 22, 2020. Revised: September 21, 2020. Accepted: September 25, 2020. Published: October 7,2020 


\section{Introduction}

Ecuadorian higher education has been showing results in recent years, but there are still limitations that are reflected in some problems, present in the reality of Ecuadorian universities, problems that are tried solve, sometimes, apart from a model of implementation of the semi-classroom modality in the careers of Social Sciences and Education, which prepares it and serves as a guide to face the challenges that his professional life holds.

The field of activity of the professional of Social Sciences and Education has been expanded; new requirements have appeared in relation to the role of the school, the character of the educational practice and the dynamics of life in society has changed; different historical moments are lived, moments of scientific and technological development, of change, of integration, and these elements impose the need for a change in the way of conceiving the process of professional training and therefore the curriculum.

The study is of great practical and methodological utility for the development of the careers in the semiclassroom modality, since it reveals the formative logic and its dynamics, which would contribute to the improvement of the curriculum and the formative praxis.

\section{Problem of Research}

The reality of the Ecuadorian university today reveals the need to perfect the practice in the semi-classroom training, since this modality is applied only with the support of the curriculum without taking into account a theoretical model that directs the training practice and reconstructs its dynamics, which affects the quality of the training process.

Regarding the variables of the research topic, no research has been found that has addressed these topics applied to the problem posed, so that the present research is considered sufficient methodological conditions to be considered unpublished. The proposal is therefore to develop a model for organising vocational training from the taking into consideration the essential components of this modality and the essential relationships that occur within it in the careers of Social Sciences and Education of the institutions of Higher Education.

\section{Scientific Questions}

What model is needed for the implementation of the semi-classroom modality in the careers of social sciences and education of the Ecuadorian university?

What are the essential components of the semiclassroom modality for the careers of social sciences and education of the Ecuadorian university?

What essential relationships energize the semiclassroom modality for the careers of social sciences and education of the Ecuadorian university?

\section{Research Development}

The literature review demonstrates the existence of relevant studies relating to the research topic [1] and [2] which provide valuable insights into knowledge management in information technologies; [3] Dynamics of semi-face training at University Headquarters and [4] Semi-face or virtual learning; the authors' research and practical experience based on contributions [5] Dynamics of audiovisual training in Vocational Technical Education, [6] information model on technological communication ; [7] methodological strategy for teaching mathematics learning with the use of virtual environments; works [8] [9] [10] that synthesize professional training seen from the didactics and the use of theoretical research methods, with particular emphasis on modelling methods and functional structural systems, allow structuring a systemic model of implementation of the semiclassroom modality in the careers of Social Sciences and Education of the Ecuadorian university, considering as an option for the process, which responds to current training conditions, where curriculum design, training context, teachers and students play an essential role

The model that is presented constitutes a simplified theoretical representation of the logical-methodological relationships that energize the process of training professionals from semi-attendance, in order to achieve

competent socio-professional performance and are built from the epistemic references of the systemic approach, consequently the model is made up of five subsystems that interact, revealing the systemic dynamics of the professional training process in blended learning. 


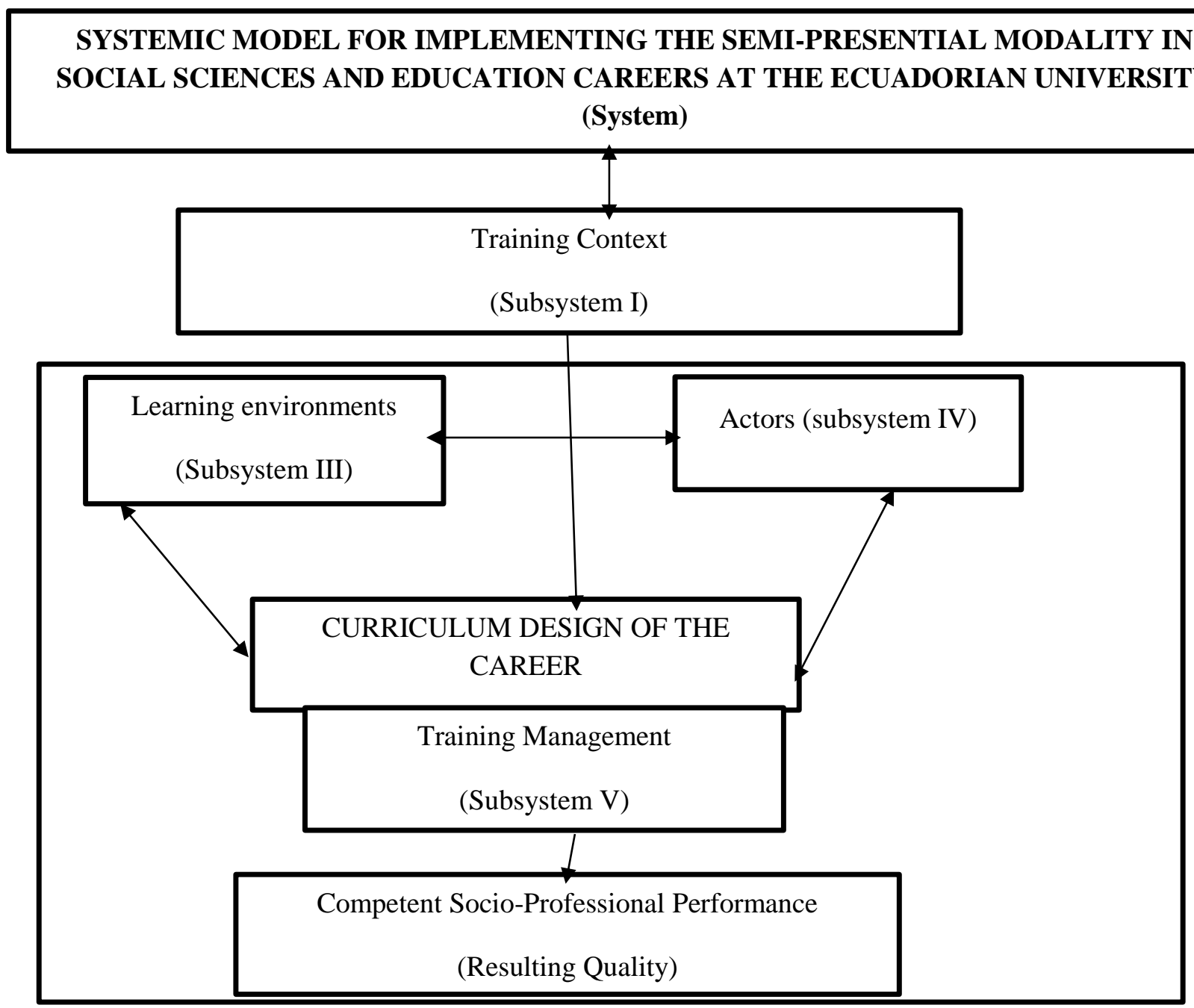

Fig. 1. Graphic representation of the systemic model of implementation of the blended learning modality in the social sciences and education careers at the Ecuadorian university.

The interactions that take place between the subsystems of the model make it possible to reveal a relationship of subordination of the Curriculum Design subsystem with respect to the others and the training context with respect to the the curriculum to the training context.

Coordination relationships are established between the learning environments, actors and training management subsystems that are synthesized in the training of socioprofessional competence and the components of the subsystems in their interaction reveal coordination relationships.

\section{Subsystem Training context}

The training context represents the characteristics or particularities of the society, institutions and subjects involved in the process of training the professional in the semi-presence.

Hence the need for recognition of the particularities of society in the design and execution of the training process of university careers in the blended mode, which means taking into account the particularities of the social context at the level of the country, territory, institution and the particularities of the individual context. In other words, in the process of professional training, it is necessary to interpret the relationship that must be established between the various socio-cultural, institutional and individual contexts, which will promote contextualized training that contributes to meaningful learning.

The country of Ecuador is in search of development and social welfare, so the formation of man is one of the main challenges of the Ecuadorian social project. Ecuadorian universities, as institutions of higher education, are committed to the mission of contributing to development through the training of professionals required by social demand.

In this sense, for the present research, the system of meanings that should dynamize the axiological and scientific-technical formation of the training is considered as a context of formation, which integrates the epistemological culture of the science of the profession from the relationship between the social, institutional, and socio-professional contexts. 


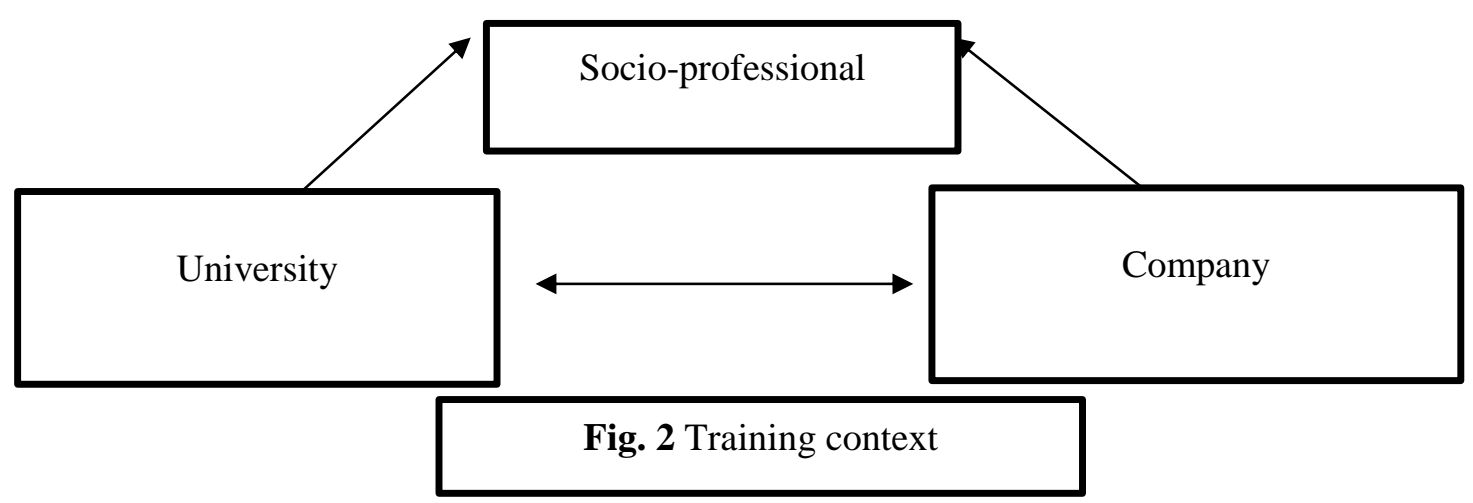

From this perspective, the university becomes a space of scientific-technical integration of culture and a centre of interpersonal relations between the subjects of the professional training process. The Faculties are responsible for organizing the process of professional training according to the educational model of the institution and the professional problems of the field of action, hence the need for a permanent relationship between the university as a training institution and society as a field of action of the professional, as a logical action in the context of training. Therefore, university professors and social actors must work in close coordination in the process of training the skills of the professional in the semi-presence career.

Society as a space for socio-professional insertion must serve to systematize the professional culture. Furthermore, the understanding of professional problems by the professional and their solution mechanisms is of great importance to achieve professional profiles.

The labour institution as a space for socio-professional training must serve as a space for the systematisation of professional culture and competences, based on the understanding of the social problems involved in the development of the context and the development of the professional.
The Institution-University-Society relationship constitutes the total expression that the subsystem signifies and therefore the conception of the model, a relationship that is configured as a principle that directs training, expressed in the curricular design as a subsystem and the training dynamics in the multiplicity of training contexts given the characteristics of semiattendance.

Curriculum Design Subsystem of the Career in Social Sciences and Education in the semi-classroom modality

The curricular design for blended learning by professional skills, understood as a policy of professional training as a socio-professional approach that signifies the process of professional training and its dynamics as a whole, is based on the need for greater prominence in the performance of professionals in the fields of action demanded by society.

Curriculum design must be related to social demands, the characteristics of the context and the needs of social development as it relates to the diversity of fields of professional activity and is structured around three essential components (Modality, Curriculum Plan, Professional Competencies).

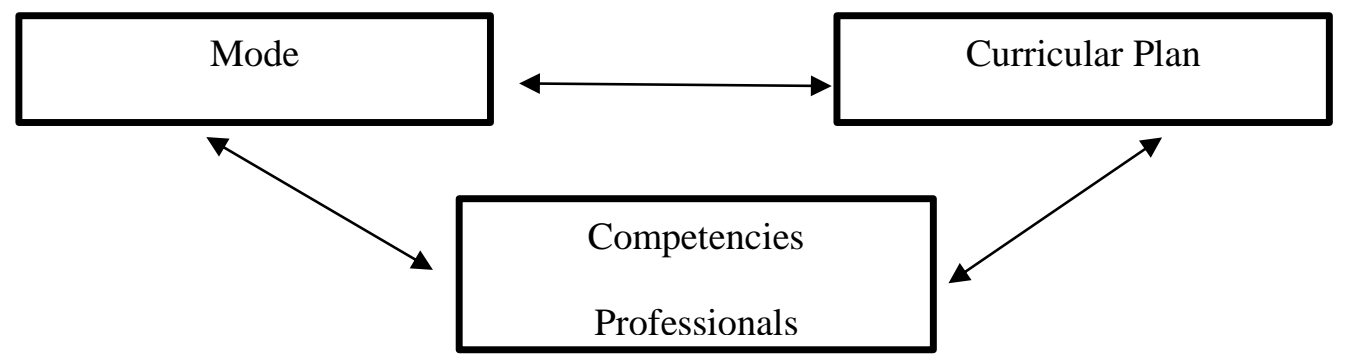

Fig. 3. Curriculum Design of the Career 
The semi-presential modality is a theoretical representation of the process of formation of the professional who needs to be trained to satisfy the social demands, in a direct way, and with respect to the scientific, cultural, technical, economic, environmental development of the whole society.

The objectives that integrate the different social and personal aspirations, in correspondence with the profession, in a unique process; oriented towards attainable ideals and necessary for the progress of society, place the professional in what is expected from him in his performance in the training process, which reaches its deployment from three essential dimensions that give the functional integrity to the training.

Axiological Dimension: the student must be a critical and reflective researcher who masters the computer tools for learning and is oriented in the search for the new, promoting the development of the culture of the profession in the context; he must be a professional who is a bearer of ethical, aesthetic, environmental and professional awareness.

Cultural Dimension: it should aim at forming culture in all its dimensions, which acquires its concrete expression in the academic culture, the scientifictechnical culture and the culture of the profession in connection with society.

Socio-professional Dimension: it is oriented to integrate professional training to the social context in a double relationship that supports the idea of learning from society and for society from a constant interaction that dignifies and commits the professional to the transformations that it demands for the well-being of citizens and for development.

For the purposes of training professionals, the training objectives, which mark the main changes to be achieved, function as the main regulatory mechanism for all those involved in professional training and its dynamics, which imposes the need for all those involved in the professional training process to have indepth knowledge of the curriculum and the particularities of the modality, its general requirements and the context in which the professional training takes place.

The curriculum design relates the educational model to the professional competencies it must possess for its performance in social practice.

The process should be oriented to the formation and development of socio-professional competence, understood as the integrated configuration of performance, which allows the integration of the cultural, axiological, research and environmental aspects in the socio-labour field in order to efficiently solve the professional problems demanded by the fields of action of the professional.

The cultural that includes the professional culture (knowledge of the profession, habits and skills in handling the categorical system), axiological culture (knowledge about values, valuation skills and constitutive elements of the ethics of the profession), research culture (knowledge of research paradigms, research skills and mastery of research methods in the social sciences and environmental culture (implies knowledge about society and the environment, skills to interact with society and the environment), one of whose fundamental ideas is that human behavior is contextual.

Research includes process (represented by scientific research methods) and socio-labour processes (represented by socio-labour interaction methods).

The axiological includes the ethical, represented by the ethical values of the profession and the social, represented by the social values that constitute a reference for professional training and regulate its contextual behaviour.

Curriculum design relates the educational model to the essential professional competencies and the curriculum, understood as the synchronized arrangement of analytical programs and real-time or deferred training links that express the logic of the process.

Consequently, the content of the disciplines and subjects must be selected taking into account their contribution to the total conformation of the competences of the professional to be trained and to the exit profiles.

The interaction that takes place in the curricular plan, in light of its dimensions, reveals a relationship of synchronization of the micro-curricular design with time and the sequence of the process, which allows teachers to direct training participation and to condition professional practice. 


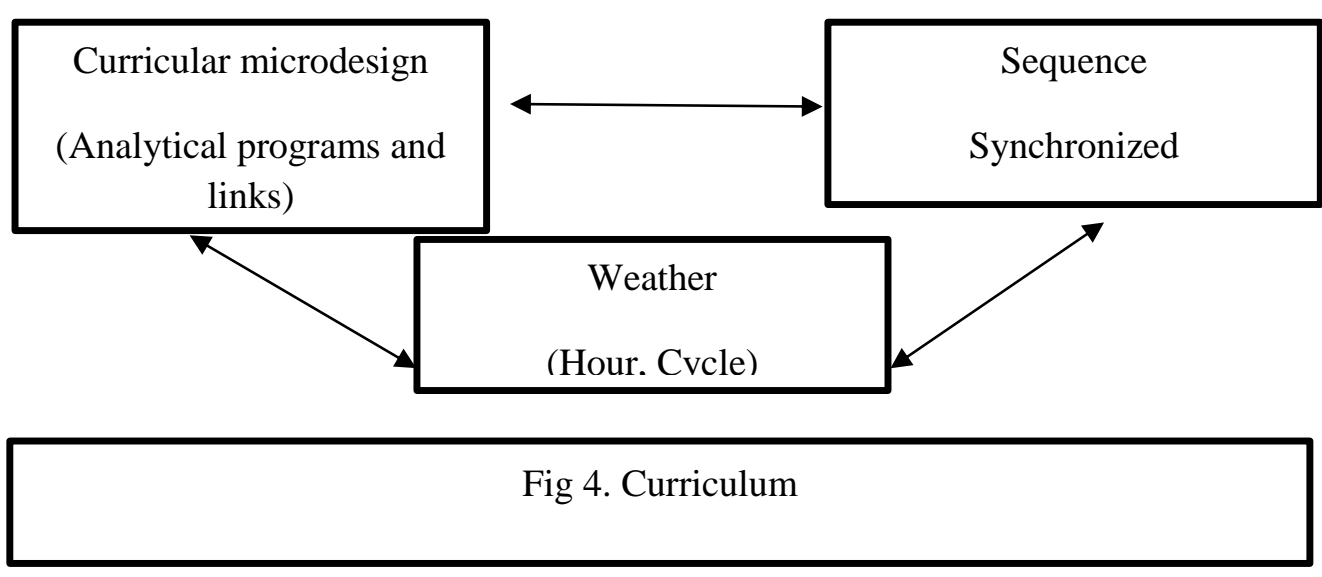

\section{Dynamics subsystem of academic training}

The dynamics of academic training is established from the syllabus and teaching learning of the subject, is based on professional problems, objectives and content, energized by the teaching and training resources, which act according to the formation of professional culture, which requires media interaction between the participants of the process in the online training contexts and the presence in the practice.

This complex process is represented by three components that in their dynamic movement become the procedures of technological mediation, apprehension of culture and cultural practice systematization of the profession.
The interaction between the components reveals a relationship that expresses the basic essentiality of technological mediation for its apprehension and systematization in the professional field.

The dynamics of academic training in turn is marked by the university-technology-society relationship, as an expression of the general dynamics of the training process.

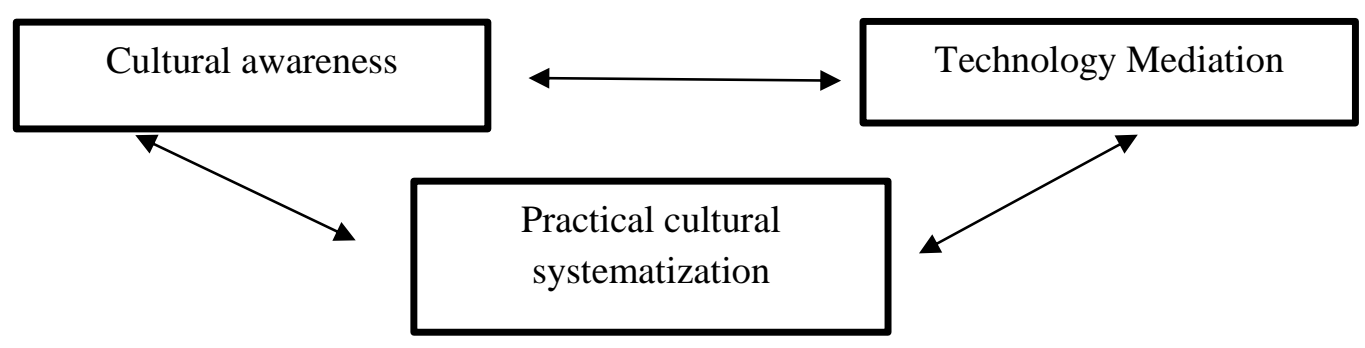

Fig 5. Dynamics of Academic Training 
The dynamics of the scientific-technical training is established from the syllabus and the teaching and learning of the subject in link with the formative contexts and it is sustained in the mediated problematization contextualized to the fields of performance of the professional, what directs the apprehension of the investigative competence and its systematization in the professionals, its revelation takes place through the technological mediation.

The establishment of the dynamics of the scientific and technical training, from the syllabus and the teaching learning of the subject online, allows the professional problems, the objectives and the content, dynamized by the didactic and formative resources to act according to the formation of the professional research competence, conditioned by the interaction of the participants of the process in the diversity of formative contexts in pursuit of its transformation.

This complex process has three components, which in their dynamic movement become the procedures of problematization, apprehension and systematization of research competence, and is signed in turn by the university-technology-society relationship, as an expression of the general dynamics of the educational process.

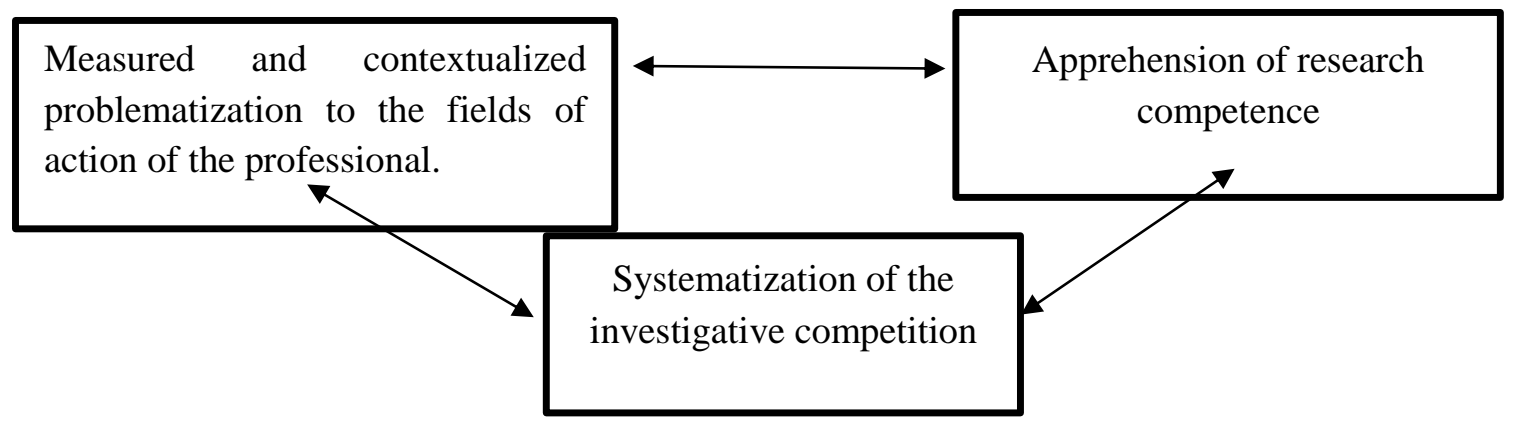

Fig 6. Dynamics of Scientific and Technical Training

\section{Vocational training dynamics subsystem}

The dynamics of practical professional training is established from the syllabus and the teaching and learning of the subject online, in link with the training contexts and is based on the mediated contextualization of the culture to the fields of action of the professional, which directs, apprehension and systematization of meanings and socio-professional senses and their integration in the development of professional competences.

The establishment of the dynamics of practical vocational training, from the syllabus and the teaching learning of the subject, allows professional problems, objectives and content, to be put in function of the formation of the professional culture, it is where the interaction of the participants of the process in the formative context takes place, which directs the formation of the professional competences.

This complex process, which has three components, that in its dynamic movement become the procedures of mediated contextualization, systematization of the competencies; apprehension of meaning and professional sense, signed by the relation university technology - society, as expression of the general dynamic of the process contextualized to the formative space where it is developed of praxis.

Of great importance is the mastery of the context and its possibilities of influence in the formation of the professional: the university plays an essential role in the formation of the professional throughout the career and in the preparation and orientation of the teacher-tutors; in line with the professional practices, which play an essential role in the formation of the professional from the first year of the career, which have functions that characterize the field of action; in this context the teacher-tutor has specific functions, which gives $\mathrm{him} / \mathrm{her}$ a preponderant role in the formation of the professional in the semi-presence. 


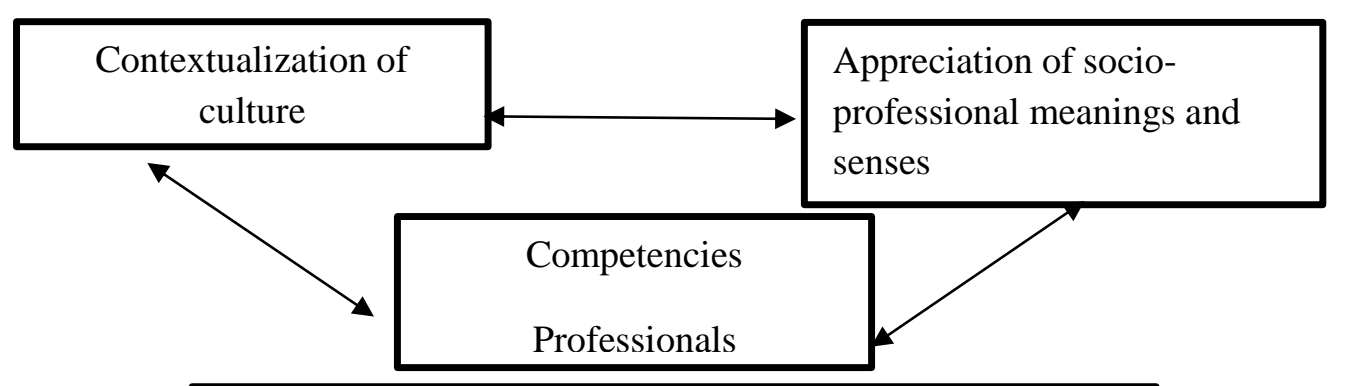

Fig. 7. Dynamics of practical socio-professional training

\section{Competent Professional Performance}

As a result of the dynamics of the process of formation of the professional, the resulting quality is the professional competences; which as a multiple experiential-personal process reflects the relations, qualities of the professional and his/her possibility of transcendence to the professional context, which possess characteristics that are constituted in general premises for his/her formation and development:

\section{_Experiential-personal process.}

_ It is built by the student from technological mediation.

- It manifests itself in the relationships it establishes with the contexts.

It is perfected and developed in professional practice guided by the teacher-tutor.

_ It is regulated by securities.

\section{R esearch Methodology}

It is precisely in the competencies that the academic is integrated; the investigative, the axiological and the practical. That is why the structuring of each media activity must take into consideration the leading role of

the student, oriented towards the active search for knowledge, stimulation, the development of reflective thinking, communication and independence, and the involvement of the student in his or her training; so that he or she is increasingly self-determined in his or her performance.

\section{Research Findings Analysis and Interpretation of the Results of the User Criteria}

The model that is presented constitutes an integrating synthesis of the main factors that participate in the management of the professional training process in the blended mode, organized from a didactic reference. In order to carry out the feasibility analysis of the proposed model, 11 users were selected based on: professional qualification level, professional competence, willingness to participate in the survey, capacity for analysis and involvement in the implementation of the model. The sample was composed of a Doctor of Science (PhD), ten Masters, a Rector, a Vice Rector of the degree, two Deans, two Vice Deans, a Graduate Director and four Career Directors; all with more than 10 years of experience in higher education.

For this purpose, a guide was prepared containing six general aspects, representative of the model, each with the indicators that allow the rating of each aspect from a descending scale of 5 to 1 , the 5 represents - excellent, the 4 - very good, the 3 - good, the 2 - fair and the 1 insufficient; in the processing of the instrument the fashion and the average for each aspect were used, as well as the integral fashion and the integral average for the purpose of generalization.

\section{A guide for users to make their own assessment}

You have been selected to evaluate the "SYSTEMIC MODEL OF IMPLEMENTATION OF THE SEMIPRESENTIAL MODALITY IN SOCIAL SCIENCES AND EDUCATION CAREERS AT THE ECUADORIAN UNIVERSITY" according to your functions as a manager and your professional performance. 
In this guide there is a group of aspects that make up the model proposal, on which you must make your judgments; taking the indicators as a reference, you must give a grade to each aspect, for which you will use a descending scale of 5 to 1 ; where 5 is equivalent to Excellent, 4 - Very Good, 3 - Good, 2 - Fair, 1 Insufficient.

Fourth level title: Management function or position:

Years of experience in Higher Education:

Table 1: Value judgments

\begin{tabular}{|l|l|l|}
\hline I- & () & Argumentation of the proposed model. \\
\hline II- & () & Structuring of the proposed model. \\
\hline III- & () & Internal logic of the proposed model \\
\hline IV- & () & $\begin{array}{l}\text { Importance of the proposed model for } \\
\text { the future of careers in the area of the } \\
\text { institution }\end{array}$ \\
\hline V- & () & Ease of implementation \\
\hline VI- & () & $\begin{array}{l}\text { Comprehensive assessment of the } \\
\text { proposed model }\end{array}$ \\
\hline
\end{tabular}

Note: The written model is attached

Thank you for your cooperation

The results behaved as follows

The aspect: Argumentation of the proposed model, was qualified as follows: four users give the value of 4 - very well that represents $36.36 \%$, six give value 5 - excellent that represents $54.54 \%$ and one gives the value of 3 well, that represents $9.09 \%$, being obtained as fashion 5 and as average 4.45; which is in the range of very well, from which it is inferred that the argument of the model is adequate, according to the ends for which it is elaborated, while $100 \%$ consider it its argument between good and excellent-. The aspect: Structuring of the proposed model, was rated, by six users with 4 very well (54.54\%), four users with 5- excellent (36.36\%) and a user with 3-good (9.09\%), obtaining a fashion of 4 (very good) and an average of 4.42 , which infers that the model presents an adequate structure, in the general and particular planes, $100 \%$ consider it their argument between good and excellent. The appearance: Internal logic of the proposed model, was rated by six users with 4- very good $(54.54 \%)$, four users with 5excellent (36.36\%) and a user with 3-good (9.09), obtaining a fashion of 4 (very good) and an average of 4.42, which suggests that the model presents an adequate internal logic of relevant importance the process of training the professional in the semiclassroom modality.

The aspect: Importance of the proposed model for the future of careers in the area of social sciences and education of the institution was qualified as follows: eight users give it the value of 5 - excellent ( $72-72 \%$ ) and two give it value 4 -very well $(18.18 \%)$, and one gives the value of 3 -well (9.09\%), obtaining as fashion 5 and as average 4.63 that is in the range of very well, from which one infers its importance for the design of the races of the area.

The aspect: Ease for its implementation, was qualified as follows: five users give the value of 5 - excellent $(45.45 \%)$, five give value 4 -very well $(45.45 \%)$, and one gives the value of 3 -well $(9.09 \%)$, obtaining as fashion 5-4 and as average 4.36 it is in the range of very well, which guarantees its applicability. The aspect: Comprehensive assessment of the proposed model, was qualified as follows: seven users give the value of 5 excellent $(63.63 \%)$ and four give value 4 -very well $(36.36 \%)$, obtaining as fashion 5 and as average 4.63 that is in the range of very good, which guarantees its integrality, an aspect of cardinal relevance to the guiding process.

The proposed model was valued between good and excellent by all users, which allows us to infer that it presents an adequate argumentation, an adequate structuring, an adequate internal logic, a cardinal importance and satisfies the requirements of its implementation in the management of the process of vocational training in the semi-classroom modality, supported by an integral fashion of 4 equivalent to very well and an integral average of 4.46 equivalent to very well, with a tendency to excellence. All of which shows great acceptance by users. 


\begin{tabular}{|c|c|c|c|c|c|c|c|c|c|c|c|c|c|}
\hline \multicolumn{14}{|c|}{ Table 2: RESULTS OF USER CRITERIA } \\
\hline Aspects & 1 & 2 & 3 & 4 & 5 & 6 & 7 & 8 & 9 & 10 & 11 & $\begin{array}{l}\text { FASH } \\
\text { ION }\end{array}$ & $\begin{array}{l}\text { MEDIA } \\
\text { FULL }\end{array}$ \\
\hline Rector & \multicolumn{4}{|c|}{ Vicerector } & $\begin{array}{l}\text { De } \\
\text { an }\end{array}$ & Dean & $\begin{array}{l}\text { Vic } \\
\text { ede } \\
\text { can } \\
\text { o }\end{array}$ & $\begin{array}{l}\text { Vic } \\
\text { ede } \\
\text { can } \\
\text { o }\end{array}$ & $\begin{array}{l}\text { Dire } \\
\text { ctor } \\
\text { of } \\
\text { Posg } \\
\text { rade }\end{array}$ & $\begin{array}{l}\text { Dir } \\
\text { ect } \\
\text { or } \\
\text { of } \\
\text { car } \\
\text { rer } \\
\text { a }\end{array}$ & $\begin{array}{l}\text { Dire } \\
\text { ctor } \\
\text { of } \\
\text { carr } \\
\text { era }\end{array}$ & $\begin{array}{l}\text { Direct } \\
\text { or of } \\
\text { carrer } \\
\text { a }\end{array}$ & $\begin{array}{l}\text { Director of } \\
\text { carrera }\end{array}$ \\
\hline MBA & \multicolumn{4}{|c|}{ MBA } & $\begin{array}{l}\text { Ma } \\
\text { ste } \\
\text { r }\end{array}$ & $\begin{array}{l}\text { Mast } \\
\text { er }\end{array}$ & $\begin{array}{l}\text { Ma } \\
\text { ste } \\
\text { r }\end{array}$ & $\begin{array}{l}\text { Ma } \\
\text { ste } \\
\text { r }\end{array}$ & PhD & $\begin{array}{l}\text { Ma } \\
\text { ste } \\
\text { r }\end{array}$ & $\begin{array}{l}\text { Mast } \\
\text { er }\end{array}$ & $\begin{array}{l}\text { Maste } \\
\mathbf{r}\end{array}$ & Master \\
\hline I & 4 & 4 & 5 & 5 & 5 & 5 & 4 & 3 & 4 & 5 & 5 & 5 & 4.45 \\
\hline II & 4 & 3 & 4 & 4 & 5 & 5 & 4 & 4 & 4 & 5 & 5 & 4 & 4.42 \\
\hline III & 4 & 4 & 4 & 5 & 5 & 4 & 5 & 3 & 4 & 4 & 5 & 4 & 4.42 \\
\hline IV & 4 & 3 & 5 & 5 & 5 & 5 & 5 & 5 & 4 & 5 & 5 & 5 & 4.63 \\
\hline $\mathrm{V}$ & 4 & 5 & 3 & 5 & 5 & 4 & 5 & 4 & 4 & 5 & 4 & $5-4$ & 4.36 \\
\hline VI & 4 & 4 & 4 & 5 & 5 & 4 & 4 & 4 & 4 & 5 & 5 & 4 & 4.63 \\
\hline $\begin{array}{l}\text { FASHIO } \\
\mathbf{N}\end{array}$ & 4 & 4 & \multicolumn{2}{|l|}{4} & 5 & 5 & $4-5$ & $4-5$ & 4 & 4 & 5 & 5 & MI-4 \\
\hline MEDIA & 4 & $\begin{array}{l}3.8 \\
3\end{array}$ & \multicolumn{2}{|c|}{4,83} & $\begin{array}{l}4,8 \\
3\end{array}$ & 5 & 4,5 & 4,5 & 3,83 & 4 & 4,83 & 4,83 & 4,46 \\
\hline
\end{tabular}

\section{Conclusions}

The technical study carried out and the contemplation of the contextual reality of Ecuador, from a future perspective, made it possible to reveal the interactions that occur between the subsystems of the model and to connote new relationships (relationship of subordination of the Curriculum Design subsystem with respect to the other subsystems, relationship of coordination between the Training Context subsystem and the Curriculum Design subsystem, which expresses the necessary relevance of the curriculum to the context and relationships of coordination between the other subsystems that are synthesized in the training of professional competence).

The model that is argued discovers the logic of professional training and allows to direct the training of professional skills in the context of semi-attendance, the feasibility analysis of the proposed model was made from the criterion of 11 users, selected according to level of professional qualification, professional competence, willingness to participate in the survey, capacity for analysis and involvement in the implementation of the model, which are valued between good and excellent by all the users, which allows to sustain that the proposed model presents an adequate argumentation, an adequate structure, an adequate internal logic, a cardinal importance and satisfies the demands of its implementation in the management of the professional training process in the semi-attendance modality, guaranteed by an integral fashion of 4 equivalent to very good and an integral average of 4.46 equivalent to very well with a tendency to excellence.

The proposed model is an alternative for the implementation of the semi-classroom modality, valid for applying in other countries, provided that the vocational training context is considered to be different and therefore that the cultural reality of each country is considered.

\section{Bibliography}

[1] Batova Marin a Mikhailovna, Baranova Irina Vyacheslavovna, Gestión del conocimiento en tecnologías de la información en el sistema de interacción de las estructuras educativas y científicoproductivas WSEAS Transactions on Business and Economics, págs..545-551, Volumen 16, 2019.

[2] Ricardo Alberto Morales Bonis, Contratos de seguro para la auditoría fiscal en Colombia WSEAS Transactións on Busines and Economics, págs. 539546, Volumen 15, 2018. 
[3] Fuentes, L. (2007) Dinámica de la Formación Semipresencial en las Sedes Universitarias Municipales. Tesis presentada en opción al grado científico de doctor en ciencias pedagógicas. Santiago de Cuba.

[4] Hinojo, M. A. \& Fernández, A. (2012). El aprendizaje semipresencial o virtual: nueva metodología de aprendizaje en Educación Superior. Revista Latinoamericana de Ciencias Sociales, Niñez y Juventud, 10 (1), pp. 159-167.

[5] Guerra G. C Mendoza P. M (2013) Dinámica de la formación audiovisual en la Educación Técnica Profesional. Tesis en opción al grado científico del Doctor en Ciencias Pedagógicas, Ciudad Bayamo.

[6] Juan Carlos Chancusig Chisag y Javier Arturo Gamboa Cruzado, Results Validation about the Adoption Model of Information and Communication Technologies Applied to the Technical University of Cotopaxi. WSEAS Transactions on Environment and Development, págs.158-171, Volume 16, 2020.

[7] Guaypatín Oscar Alejandro y otros. (2020) Influencia de los entornos virtuales en el aprendizaje de Matemática en la facultad de ciencias de la ingeniería y aplicadas de una Universidad Ecuatoriana. Caracas, Venezuela

[8] Mendoza Pérez, Melquiades (2004) "Alternativa para la dirección didáctica del proceso de formación del profesional de la educación”. Tesis Doctorado.

[9] Mendoza Pérez, Melquiades (2011) Constructos metodológicos teóricos y praxiológicos en la ciencia, en soporte digital. Consultado en febrero de 2020.

[10] Mendoza Pérez, Melquiades (2013). La concepción científica de lo genético transformacional múltiple y el desarrollo local. Conferencia Magistral. Congreso Cubano de desarrollo LOCAL. En soporte digital. Consultado en marzo de 2020.

\section{Creative Commons Attribution License 4.0 (Attribution 4.0 International, CC BY 4.0)}

This article is published under the terms of the Creative Commons Attribution License 4.0

https://creativecommons.org/licenses/by/4.0/deed.en US 